\title{
Traits of Personality and Preferred Values among Fearless and Courageous Policemen
}

\author{
Piotr Próchniak ${ }^{1}$ \\ ${ }^{1}$ Pomeranian University, Slupsk, Poland \\ Correspondence: Department of Psychology, Pomeranian University, Westerplatte 64, 76-200 Slupsk, Poland. \\ E-mail: piotrprochniak@wp.pl
}

Received: September 27, 2012

Accepted: November 2, 2012 Online Published: November 27, 2012

doi:10.5539/ijps.v4n4p113

URL: http://dx.doi.org/10.5539/ijps.v4n4p113

\begin{abstract}
The present study aimed to identify differences in the personality factors and preferred values of courageous and fearless police officers. A sample group comprising 43 courageous (Mage=33.7yr., SD=4.8) and 43 fearless policemen (Mage=31.2yr., SD=4.8) was identified from among 157 potential subjects. The group completed a questionnaire designed for the purposes of the study and entitled Anxiety Scale for Policemen, as well as the Zuckerman-Kuhlman Personality Questionnaire (ZKPQ) and Schwartz's Value Survey. The fearless policemen scored significantly higher on Sensation Seeking and markedly lower on Aggression/Hostility, Neuroticism and Impulsivity than the courageous group. The former were also characterized with significantly lower results than the latter for values scales such as Tradition and Power. There were no differences for other values scales. The conclusions indicate that policemen are not a homogenous group.
\end{abstract}

Keywords: courage, personality, values, policemen

\section{Introduction}

\subsection{Courage}

Courage has a long tradition and many different meanings and definitions. It is identified in Christianity, Confucianism, Judaism, Taoism and Buddhism. In philosophy, courage is an ancient mortal virtue. Aristotle, for instance, said that courage was the disposition to act in physically dangerous situations involving fear and confidence. The psychology of courage is manifested as an integral aspect of religions and philosophical traditions. One psychologist who could be said to have been interested in courage was Adler. On the basis of Nietzsche's concept of the will to power, Adler suggested that every individual desiring to exert their will in self-overcoming and interaction with the world is able to create energy. Tillich (1980) defined courage as “...the power of life to affirm itself in spite of this ambiguity...” (p. 27). Influenced by Tillich and Adler, Rollo May described courage as follows: "Courage is not the absence of despair; it is rather, the capacity to move ahead in spite of despair” (May, R. 1975, p. 3).

Within the framework of positive psychology, courage has been defined as "Emotional strengths that involve the exercise of will to accomplish goals in the face of opposition, external or internal” (Dahlsgaard, Peterson \& Seligman, 2005, p. 205). Shelp (1984) describes it as "the disposition to act voluntarily, perhaps fearfully, in dangerous circumstance, where the relevant risks are reasonably appraised, in an effort to obtain or preserve some perceived good for oneself or others recognizing that the desired perceived good may not be realized" (p. 354). He makes judgments in respect of whether a fearful situation is objectively or subjectively dangerous. In contrast, Rahman (1984) argues that an objective threat is not a prerequisite and that subjective anxiety in situations without real risk is sufficient to determine a courageous act. He states that courage has three components, namely 1) behaviour; 2) perceived risk associated with carrying out the behaviour; and 3) the presence of fear. Putman (1997) distinguishes three different types of courage. Physical courage is an act which carries the risk of physical harm or even death. Moral courage concerns acts of moral obligation which incur the risk of disapproval on the part of society. Psychological courage occurs with acts which involve the risk of losing psychological stability.

This article analyses the first of the types defined by Putman, physical courage. Research on this topic is rather rare. In a study carried out by Hallam and Rachman (1980), decorated military bomb-disposal operators were 
shown to have a lower health anxiety than non-decorated soldiers. Cox, Hallam, O’Connor and Rachman (1983) compared the performance of difficult tasks among decorated and non-decorated officers. Those with decorations showed less cardiac reactivity while carrying out the task than those without. Gal (1995) examined decorated and non-decorated Israeli soldiers. The former scored higher on the leadership scale, devotion to duty, decisiveness and perseverance under stress than the non-decorated group. Intelligence and emotional stability did not differ between the two groups.

The aforementioned research has its limitations. In none of the studies is it obvious whether or not the decorated officers felt fear in dangerous situations. If we do not know the intensity of their fear, it is difficult to say whether or not these officers were "courageous"; it is possible that they were fearless.

In an effort to distinguish between a courageous and a fearless person, McMillan and Rachman (1988) conducted a study involving recruits in a parachute regiment. They identified three recruit profiles; Courageous, Fearless and Over-Confident. The majority of the subjects belonged to the first category. They were moderately fearful before making a parachute jump, but were also modestly optimistic and benefited from the experience. Moreover, they successfully completed the jump. The fearless individuals were highly confident before jumping and experienced low levels of fear, while those who fell within the third group experienced extremely high fear, marked body reactions and benefited least from the experience of jumping.

\subsection{Personality and Values among Police Officers}

This study analyses the personality traits and preferred values of courageous and fearless policemen. The work of police officers is both physically and emotionally intense. A high level of emotional dedication is demanded in the performance of occupational tasks in difficult and unsafe situations such as chasing down criminals, crackdowns, participating in interventions, establishing contact with hostile and aggressive people, informing families about the deaths of relatives, helping desperate people and so forth. As a consequence, their job is potentially a very stressful one and we can distinguish police officers who are fearless and those who are courageous, in other words, those who carry out dangerous occupational tasks successfully despite their personal fear. Since personality traits and values are primary motivational factors in risk-taking behaviours, it is of interest to discover the motivational factors among courageous and fearless police officers.

One motivation to be a police officer can be the expression of a personality trait, namely, sensation seeking (Zuckerman, 1994). This has been defined as "seeking varied, novel, complex and intense sensations and experiences and the willingness to take physical, social, legal, and financial risks for the sake of such experience" (Zuckerman, 1994, p. 27). A substantial amount of the research on sensation seeking has been associated with the work of police officers (Carlson \& Lester, 1980; Homant, Kennedy \& Howton, 1993; Goma-i-Freixanet \& Wismeijer, 2002; Levin \& Brown, 1975).

Studies carried out on police officers may cover more than sensation seeking on the part of the individual, however. For example, having used the EPQ in a study of candidates for the police force, Burbeck and Furnham (1984) reported high scores for Extroversion and low for Neuroticism. Goma-i-Freixanet and Wismeijer (2002) employed the same test to investigate personality differences among Spanish policemen, individuals who undertake risk sports and a control group of individuals who avoid risk. The police officers scored lower on Neuroticism and Psychoticism than the control group and lower on the Neuroticism, Psychoticism and Lie Scales than the sports risk takers.

This study set out to use Zuckerman's model (1992) in order to look for the personality characteristics differentiating fearless and courageous police officers. Zuckerman distinguished five personality traits; Impulsive Sensation Seeking, Neuroticism, Activity, Sociability, and Aggression/Hostility (Zuckerman, Kuhlman, Joireman, Teta \& Kraft, 1993). In his model (Zuckerman, 1992), impulsivity constitutes one dimension with sensation seeking and is defined as Impulsive Sensation Seeking. Impulsivity is associated with an inability to plan effectively (Llewellyn \& Sanchez, 2008). Zuckerman distinguished impulsive, unsocialized sensation-seeking (ImpUSS) and non-impulsive, socialized sensation-seeking (Zuckerman, 1979; Roberti, 2004). Research on individuals who engage in risk sports and works suggest that they represent the non-impulsive, socialized sensation-seeking trait. For example, in respect of the impulsivity trait, Goma-i-Freixanet's study (1995) found no significant differences between firefighters, policemen, alpinists or other, related, risk sports practitioners and individuals not engaged in risk activity. It would thus seem to be worth treating impulsivity and sensation seeking as independent dimensions (Jack \& Ronan, 1998).

Studies on the motives for becoming a police officer have extended beyond sensation seeking. Personal values have also been shown to be a motivating factor. In Lester's study (1983), values such as earning money and job stability were shown to be more important to the police officer subjects. Research conducted by Hopper (1977) 
produced similar results, demonstrating that the police officers in question were motivated by materialistic benefits. Griffeth and Cafferty (1977) found that their respondents rated values relating to private issues such as self-respect and family security highly and assigned a low priority to those connected with social issues, like social recognition, for instance. A family tradition of serving with the police proved to be important in choosing this profession on Taiwan (Tarng, Hsieh \& Deng, 2001). In contrast to the studies mentioned thus far, other research (Meagher \& Yentes, 1986; Raganella \& White, 2004) has shown that it is not only job stability or salary which is important factor, but also the excitement involved in the work.

As well as employing Zuckerman's model (1992) in order to identify the personality characteristics distinguishing fearless and courageous police officers, this study included the use of Schwartz's Value Model for the purpose of distinguishing the value characteristics differentiating the two types. Schwartz views values as something which can be treated as existential; they possess concrete meaning in concrete situations and contexts, as well as a cross-situational character (Schwartz, Sagiv \& Boehenke, 2000). They make up the essential criterion which allows an individual's behaviour to be estimated and a particular order to be characterized. Some values are very important for the subject, while others are less so. The Schwartz Value Survey allows the following types of values to be distinguished: Self-Direction; Stimulation; Hedonism; Achievement; Power; Security, Conformity; Tradition; Benevolence; and Universalism. These values are the basic principles which guide individual behaviour throughout life (Schwartz, 1992).

\subsection{The Research Hypothesis}

The purpose of this study was to analyze fearless and courageous police officers on the basis of their personality or values system. Taking a previous study conducted by McMillan and Rachman (1988) as a foundation, it was assumed that fearless police officers would score lower on Neuroticism than courageous ones. At the same time, following the findings of research carried out by Carlson and Lester (1980); Homant, Kennedy and Howton, (1993); Goma-i-Freixanet and Wismeijer (2002); Meagher and Yentes, (1986); and Raganella and White, (2004), it was posited that, in comparison to their courageous counterparts, they would score higher on the Sensation Seeking, Hedonism or Stimulation values.

\section{Research Method}

\subsection{Participants}

The 157 Polish police officers who volunteered to participate in the study were all men ( $M=33.30 \mathrm{yr}$., $\mathrm{SD}=5.76)$. The fearless and courageous policemen were distinguished from among the 157 volunteers; the criterion for identifying them was a low or overhead quartile score on the Anxiety Scale for Policemen (see: Materials). The sample consisted of 43 courageous (Mage=33.7yr., $\mathrm{SD}=4.8$ ) and 43 fearless policemen (Mage=31.2yr., $\mathrm{SD}=4.8$ ).

\subsection{Procedure}

The policemen were recruited through police departments in Northern Poland and were officers who effectively carry out occupational tasks in dangerous situations.

The participants were informed as to the goals of the research. Each policeman first answered several questions regarding age, sex, and years of job experience. They completed the questionnaires individually, often at home, and then returned them to the author.

\subsection{Materials}

The participants completed three questionnaires.

\section{Anxiety Scale for Policemen}

The first questionnaire to be used was entitled Anxiety Scale for Policemen and was developed by the author for the purposes of the study. It was designed to investigate the respondents' emotional reactions across risky, unsafe, but successfully concluded occupational tasks. The measure consisted of 6 items and the statements of which they were comprised were rated on a 4-point scale, where 1 equated to "never" and 4, to "always".

Based on the sample of the 94 respondent policemen $(\mathrm{M}=29.4, \mathrm{SD}=1.7)$, a Varimax rotation was performed in order to assess the factorial structure of the questionnaire. The factor analysis revealed one factor explaining $61 \%$ of total variance. The coefficient alpha reliability is .87 . The reliability of the test-retest for the scale after four weeks equalled .83 .

For example, the items assessing anxiety in risky but successfully completed work tasks were I'm afraid; I'm angry with other people or circumstance; I think pessimistically and I feel anxious. 


\section{The Zuckerman - Kuhlman Personality Questionnaire (ZKPQ)}

The ZKPQ questionnaire is designed to measure five basic personality traits (Zuckerman, Kuhlman, Joireman, Teta \& Kraft, 1993). An experimental Polish version was used in this study. The coefficient alpha reliabilities for the five scales of the ZKPQ are Impulsive Sensation Seeking .72, Neuroticism .90, Activity .81,Sociability .82, and Aggression or Hostility .83. In Zuckerman's model (1992) impulsivity constitutes one dimension with sensation seeking and is described as Impulsive Sensation Seeking. In this study, however, impulsivity and sensation seeking were analyzed as independent dimensions (Jack \& Ronan, 1998).

\section{Value Survey}

The third questionnaire to be used was Schwartz's Value Survey (Schwartz, 1992), containing ten values. Each value was rated on a 9-point scale, ranging from opposed to my principles (-1) through not important (0) to of supreme importance (7). The reliabilities, or Cronbach's alphas, of the ten values are achievement .70, hedonism .66, power .73, stimulation .67 , self-direction .63 , conformity .57 , tradition .54 , security .61 , benevolence, .68, universalism .76.

\section{Results}

Step one was to distinguish the fearless and the courageous policemen. The criterion for this was a low or overhead quartile score on the scale established for the Anxiety Scale for Policemen, where a low quartile score identified the fearless respondents $(\mathrm{N}=43)$ and the overhead quartile, the courageous ones $(\mathrm{N}=43)$.

The results as regards personality traits and preferred values in the groups of fearless and courageous policemen, respectively, are presented in table 1.

Table 1 . Traits of personality and preferred values comparative of the fearless policemen and the courageous policemen, Student $(\mathrm{t})$ test $(\mathrm{N}=86)$

\begin{tabular}{|c|c|c|c|c|c|}
\hline \multirow[t]{2}{*}{ Variables } & \multicolumn{2}{|c|}{ The fearless policemen } & \multirow{2}{*}{$\begin{array}{l}\begin{array}{l}\text { The } \\
\text { policemen }\end{array} \\
\text { M }\end{array}$} & \multirow{2}{*}{$\begin{array}{l}\text { courageous } \\
\text { SD }\end{array}$} & \multirow[t]{2}{*}{$\mathrm{t}$} \\
\hline & $\mathrm{M}$ & SD & & & \\
\hline \multicolumn{6}{|l|}{ Personality traits } \\
\hline $\begin{array}{l}\text { Impulsive } \quad \text { sensation } \\
\text { seeking }\end{array}$ & 10.36 & 3.93 & 10.41 & 2.81 & .06 \\
\hline Neuroticism & 2.25 & 2.04 & 7.53 & 3.37 & $-8.76^{* *}$ \\
\hline Sociability & 8.90 & 2.96 & 8.39 & 2.26 & .89 \\
\hline Aggression / Hostility & 6.27 & 2.93 & 7.86 & 2.35 & $-2.75^{* *}$ \\
\hline Activity & 9.62 & 3.12 & 8.81 & 2.19 & 1.39 \\
\hline Impulsivity & 2.69 & 1.89 & 3.65 & 1.70 & $-2.45^{* *}$ \\
\hline Sensation seeking & 7.67 & 2.64 & 6.76 & 2.21 & $1.91 *$ \\
\hline \multicolumn{6}{|l|}{ Values } \\
\hline Achievement & 4.16 & 1.39 & 4.38 & .86 & -.89 \\
\hline Hedonism & 4.10 & 1.45 & 4.24 & 1.17 & -.48 \\
\hline Power & 3.31 & 1.30 & 4.04 & 1.00 & $-2.89 * *$ \\
\hline Stimulation & 4.26 & 1.47 & 4.24 & 1.24 & .07 \\
\hline Self-direction & 4.68 & 1.05 & 4.50 & .86 & .89 \\
\hline Universalism & 4.64 & 1.05 & 4.38 & .95 & 1.17 \\
\hline Benevolence & 4.80 & .85 & 4.62 & .86 & 1.00 \\
\hline Security & 4.82 & .89 & 4.73 & .74 & .54 \\
\hline Conformity & 4.68 & 1.25 & 4.64 & .91 & .14 \\
\hline Tradition & 3.72 & 1.06 & 4.32 & .85 & $-2.84 * *$ \\
\hline
\end{tabular}


The fearless group scored significantly lower on the Neuroticism, Aggression/Hostility and Impulsivity scales than the courageous group $(\mathrm{p}<.01)$ and significantly higher on the Sensation Seeking scale $(\mathrm{p}<.05)$. There were no differences between the groups for the other personality scales. In terms of values, the fearless policemen were characterized with significantly lower results for the Tradition $(\mathrm{p}<.01)$ and Power $(\mathrm{p}<.01)$ scales in comparison to the courageous group. For the other scales of values, the two groups did not differ.

\section{Multivariate analysis}

A discriminant function analysis (DFA) was used to assess the capacity of variables for the prediction of the fearless and courageous policemen. The variables for the group differences were included in the discriminant function analysis. The variables were Sensation Seeking, Impulsivity, Neuroticism, Aggression/Hostility, Power and Tradition.

One significant function was identified, with an eigenvalue of .99 and a canonical correlation of .70, $\mathrm{X}^{2}(6, \mathrm{n}=$ 86) $56.10, \mathrm{p}<.01$.

Table 2 indicates that $84.88 \%$ of the group cases were correctly classified, this being $90.69 \%$ of the fearless and $79.06 \%$ of the courageous.

Table 2. Classification results

\begin{tabular}{lllll}
\hline \multirow{2}{*}{ Cases } & & \multicolumn{2}{l}{ Predicted group } & Total \\
\cline { 3 - 4 } & & Fearless & Courageous & \\
\hline Original count & Fearless & 39 & 4 & 43 \\
\cline { 2 - 4 } & Courageous & 34 & 9 & 43 \\
\hline \multirow{2}{*}{$\%$ classified } & Fearless & 90.69 & 9.31 & 100 \\
\cline { 2 - 4 } & Courageous & 79.06 & 20.94 & 100
\end{tabular}

Note. $84.88 \%$ of original grouped cases correctly classified

The primary variables discriminating the fearless from the courageous were Neuroticism (-.95); Power (-.31) and Tradition (-.31), (Table 3).

Table 3. Structure matrix for discriminant function

\begin{tabular}{ll}
\hline Variable & Structural coefficient \\
\hline Sensation Seeking & .20 \\
Impulsivity & -.26 \\
Neuroticism & -.95 \\
Aggression /Hostility & -.30 \\
Power & -31. \\
Tradition & -.31 \\
\hline
\end{tabular}

\section{Discussion}

Police officers encounter numerous dangerous occupational situations. Some experience anxiety across occupational tasks which are unsafe, but are successfully concluded, while others do not. In this study, the former were described as courageous and the latter, as fearless. The differences in personality traits and preferred values between the two groups of policemen thus distinguished were then explored.

The courageous policemen obtained higher results for the trait of Neuroticism, in comparison with fearless policemen. In this regard, the research hypothesis was confirmed. The results are similar to those obtained by McMillan and Rachman (1988) and they are clear and easy to predict. 
Surprisingly, courageous policemen scored higher on Aggression/Hostility than fearless policemen. What factors might underlie such different results between the two groups for this trait? Aggression/Hostility is a person's tendency to react with negative emotions and high energy against threats (Zuckerman, 1994). The courageous policemen's responses indicate that, in dangerous situations, such as encountering hostility and aggression, for instance, they experience anxiety. They may then overreact with an aggressive counterattack. In all likelihood, this aggression helps them to mobilize the energy required to defend and protect themselves. At the same time, they proved to be more impulsive than the fearless group, a result which suggests that they have more problems with operational planning than their fearless counterparts.

The higher intensity of Sensation Seeking among the fearless policemen may indicate that they will search for situations involving physical hazards both in their profession and beyond. They will not avoid situations in which their own health or life is endangered in order to help others. Furthermore, they may find hazardous situations connected with saving other people to be a source of exciting experiences. The results of this study find confirmation in previous research into the need for variety and stimulation among groups of police officers (Carlson \& Lester, 1980; Homant, Kennedy \& Howton, 1993; Goma-i-Freixanet \& Wismeijer, 2002; Levin \& Brown, 1975).

The study also demonstrated that, on the one hand, in comparison to the courageous group, fearless officers have higher scores for the Sensation Seeking personality trait and lower for Neuroticism, Aggression/ Hostility and Impulsivity. On the other hand, in comparison to the fearless group, the courageous officers score higher for the values of Tradition and Power. This gives rise to an entirely new assumption.

The value of Tradition reflects an esteem for, and commitment to, cultural customs and ceremonies. The value of Power encompasses prestige, financial success and the control of others (Schwartz, 1992). The data obtained in this study show that, contrary to the fearless group, the courageous policemen place a greater emphasis on traditions and that the past holds a much greater appeal for them. Moreover, they might be motivated by the expectation of earning money and may also enter their profession for reasons of prestige. The results pertaining to the courageous policemen in this respect are consistent with the research conducted by Hoper (1977), Lester (1983) and Tarng, Hsieh and Deng (2001).

At the same time, these results suggest that fearless police officers represent a motivation different from that found in their courageous counterparts. Social motives such as Power and Tradition are less valued in this group, which reflects a positive response to risky behaviour, especially as regards seeking adventure and a preference for unpredictable situations, as well as a tendency to search for change and novelty. The courageous group, on the other hand, did not associate helping others with the search for exciting situations. Their motivations are extrinsic; tradition, salary and prestige. The results in respect of the fearless policemen accord with the studies carried out by Meagher and Yentes (1986) and Raganella and White (2004).

The results obtained in the study and outlined above indicate that police officers are not an homogenous group. The fearless and courageous policemen proved to differ in respect of both personality traits and preferred values. This means that the two groups are motivated differently. Fearless police officers are people who appreciate challenges and have a preference for unforeseeable situations and adventure. Conversely, courageous policemen not much interested in a broad range of thrill-seeking activities. For them, financial benefits, power, prestige and tradition are more important at work than sensation seeking.

\section{References}

Burbeck, E., \& Furnham, A. (1984). Police officer selection: Trait differences in successful and non-successful applicants to the metropolitan police. Personality and Individual Differences, 5, 257-263. http://dx.doi.org/10.1016/0191-8869(84)90064-3

Carlson, L. D., \& Lester, D. (1980). Thrill seeking in police officers. Psychological Reports, 47, 1102. http://dx.doi.org/10.2466/pr0.1980.47.3f.1102

Cox, D., Hallam, R., O'Connor, K., Rachman, S. (1983). An experimental analysis of fearlessness and courage. British Journal of Psychology, 74(1), 107-117. http://dx.doi.org/10.1111/j.2044-8295.1983.tb01847.x

Dahlsgaard, K., Peterson, C., \& Seligman, M. E. P. (2005). Shared virtue: The convergence of valued human strengths across culture and history. Review of General Psychology, 9, 203-213. http://dx.doi.org/10.1037/1089-2680.9.3.203

Gal, R. (1995). Personality and intelligence in the military: The case of war heroes. In Saklofske, D. H. \& Zeidner, M. (Eds), International handbook of personality and intelligence (pp. 727-737). New York, NY, US: Plenum Press. 
Goma-i-Freixanet, M. (1995). Prosocial and antisocial aspects of personality. Personality and Individual Differences, 19(2), 125-134. http://dx.doi.org/10.1016/0191-8869(95)00037-7

Goma-i-Freixanet, M., \& Wismeijer, A.A.J. (2002). Applying personality theory to a group of police bodyguards: A physically risky prosocial prototype? Psicothema, 14, 387-392.

Griffeth, R., \& Cafferty, T. (1977). Police and citizen value systems: some cross-sectional Comparisons. Journal of Applied Social Psychology, 7, 191-204. http://dx.doi.org/10.1111/j.1559-1816.1977.tb00745.x

Hallam, R. S., \& Rachman, S. J. (1980). Courageous acts or courageous actors? Personality and Individual Differences, 1, 341-346. http://dx.doi.org/10.1016/0191-8869(80)90017-3

Homant, J. R., Kennedy, D. B., \& Howton, J. D. (1993). Sensation seeking as a factor in police pursuit. Criminal Justice and Behavior, 20(3), 293-305. http://dx.doi.org/10.1177/0093854893020003006

Hopper, M. (1977). Becoming a policeman: Socialization of cadets in a police academy. Urban Life, 6, 149-168.

Jack, S. J., \& Ronan, K. R. (1998). Sensation seeking among high- and low-risk sports participants. Personality and Individual Differences, 25, 1063-1083. http://dx.doi.org/10.1016/S0191-8869(98)00081-6

Lester, D. (1983). Why do people become police officers: A study of reasons and their predictions of success. Journal of Police Science and Administration, 11, 170-174.

Levin, B. H., \& Brown, W. E. (1975). Susceptibility to boredom of jailers and law enforcement Officers, Psychological Reports, 36(1), 190. http://dx.doi.org/10.2466/pr0.1975.36.1.190

Llewellyn, D. J., \& Sanchez, X. (2008). Individual differences and risk taking in rock climbing. Psychology of Sport and Exercise, 9, 413-426. http://dx.doi.org/10.1016/j.psychsport.2007.07.003

May, R. (1975). The courage to create. New York, London: W.W. Norton \& Company.

Meagher, S. \& Yentes, N. (1986). Choosing a career in policing: A comparison of male and female perceptions. Journal of Police Science and Administration, 14, 320-327.

McMillan, T. M., \& Rachman, S. J. (1988). Fearlessness and courage in paratroopers undergoing training. Personality and Individual Differences, 9(2), 373-378. http://dx.doi.org/10.1016/0191-8869(88)90100-6

Putman, D. (1997). Psychological courage. Philosophy, Psychiatry, \& Psychology, 4(1), 1-11. http://dx.doi.org/10.1353/ppp.1997.0008

Rachman, S. (1984). Fear and courage. Behavior Therapy, 15(1), 109-120. http://dx.doi.org/10.1016/S0005-7894(84)80045-3

Raganella, A., J., \& White, M., D. (2004). Race, gender, and motivation for becoming a police officer: Implications for building a representative police department. Journal of Criminal Justice, 32(6), 501-513. http://dx.doi.org/10.1016/j.jcrimjus.2004.08.009

Roberti, J. W. (2004). A review of behavioral and biological correlates of sensation seeking. Journal of Research in Personality, 38, 256-279. http://dx.doi.org/10.1016/S0092-6566(03)00067-9

Schwartz, S. H. (1992). Universals in the content and structure of values: Theoretical advances and empirical tests in 20 countries. In M. P. Zanna (Ed.), Advances in experimental social psychology, Vol. 25 (pp. 1-65). New York: Academic Press.

Schwartz, S. H., Sagiv, L., Boehenke, K. (2000). Worries and values. Journal of Personality, 68(2), 309-346. http://dx.doi.org/10.1111/1467-6494.00099

Shelp, E. E. (1984). Courage: A neglected virtue in the patient-physician relationship. Social Science \& Medicine, 18(4), 351-360. http://dx.doi.org/10.1016/0277-9536(84)90125-4

Tarng, M., Hsieh, C., \& Deng, T. (2001). Personal background and reasons for choosing a career in policing: An empirical study of police students in Taiwan. Journal of Criminal Justice, 29, 45-56. http://dx.doi.org/10.1016/S0047-2352(00)00075-1

Tillich, P. (1980). The courage to be. New Haven, CT: Yale University Press.

Zuckerman, M. (1979). Sensation seeking: Beyond the optimal level of arousal. Hillsdale, NJ: Eribaum.

Zuckerman, M. (1992). What is a basic factor and which factors are basic? Turtles all the way down. Personality and Individual Differences, 13, 675-682. http://dx.doi.org/10.1016/0191-8869(92)90238-K

Zuckerman, M. (1994). Behavioral expressions and biosocial bases of sensation seeking. New York, Cambridge: 
University Press.

Zuckerman, M., Kuhlman, D. M., Joireman, J., Teta, P., \& Kraft, M. (1993). A comparison of three structural models for personality: The big three, the big five, and the alternative five. Journal of Personality and Social Psychology, 65(4), 757-768. http://dx.doi.org/10.1037/0022-3514.65.4.757 